\title{
NUMERICAL ESTIMATION OF SHALLOW WATER EFFECT ON MULTIPURPOSE AMPHIBIOUS VEHICLE RESISTANCE M. Nakisa ${ }^{1}$, A. Maimun ${ }^{*}$, Y. M. Ahmed ${ }^{3}$, F. Behrouzi ${ }^{3}$ and A. Tarmizi ${ }^{3}$
}

${ }^{1}$ Department of Mechanical Engineering, Bushehr Branch, Islamic Azad University, Bushehr, Iran

${ }^{2}$ Marine Technology Centre (MTC), UniversitiTeknologi Malaysia(UTM), Taman Univ., Skudai, Johor Bahru, 81310, Malaysia

${ }^{3}$ Mechanical Engineering Faculty, UniversitiTeknologi Malaysia(UTM), Taman Univ., Skudai, Johor Bahru, 81310, Malaysia *Email:Adi@mail.fkm.utm.my

\begin{abstract}
:
This research paper numerically investigated the hydrodynamic resistance of Multipurpose Amphibious Vehicles (MAV) navigating in shallow water. This type of vehicle and other coastal floating vehicles encounter the problem of a small under keel clearance with river bed. The proper estimation of ship resistance and squat is influenced largely on the power calculation in the design stage. The present work describes the effect of shallow water on the Multipurpose Amphibious Vehicles (MAV) resistance at different speeds using Computational Fluid Dynamics (CFD) techniques. A comparison in the drag on the hull is illustrated between depth restriction and infinite depth water. This paper provides a wide introduction into the problems of modeling the restricted water depth effects on the ship behaviour, specifically hydrodynamic resistance and squat using CFD as implemented by ANSYS-CFX14.0.
\end{abstract}

Keywords: Multipurpose amphibious vehicle (MAV), shallow water, hydrodynamic resistance, computational fluid dynamics (CFD).

\section{Introduction}

The resistance of a ship at a particular speed is the opposing forces acting on the ship by the fluid which oppose the forward motion. The opposing force by the fluid is due to the viscosity of the fluid and the pressure changes around the ship. The ship which is designed for operating in deep sea, it has to operate in shallow water also whenever it comes to port or harbour, gently it will have to encounter the shallow water effects (Patel and Premchand, 2015). The hydrodynamic investigation on landing craft and amphibious vehicles has a long history beginning in WWII with the Higgins LCVP (Haddock and Latorre, 1995) extendedto the 35 knots hydrofoil, LVH (Carl, 1965), and the 70 knots air cushion LCAC used today (Alexander and Alexander, 1963). Included in this group are the M59 Amphibious Personnel Carrier and the air-transportable M113 Amphibious Personal Carrier introduced in 1960. By 2000, Over 76,000 M113 variants were built. The M113 is a tracked vehicle powered by an eight-cylinder $215 \mathrm{hp}$ engine. In the amphibious operation, the M113 operates at $5.8 \mathrm{~km} / \mathrm{h}(3.13$ knots), and on land, it reaches speeds of $64 \mathrm{~km} / \mathrm{h}$. It steers on land and water by changing the speed of either track. Designed for air transport, the M113 is compact and lightweight. It has weight saving aluminum armored plate. The M113 dimensions are $4.86 \mathrm{~m}$ long, $2.686 \mathrm{~m}$ wide and $1.85 \mathrm{~m}$ high. At its weight of $11,253 \mathrm{~kg}$, it has an amphibious draft of $1.3 \mathrm{~m}$. The box-shaped hull results in a length to beam ratio $\mathrm{L} / \mathrm{B}=1.80$ and a beam to draft ratio $\mathrm{B} / \mathrm{T}=2.12$ (Foss, C. 2003).

A study of a new hull design of Multipurpose Amphibious Vehicles (MAV) was conducted to enhance its amphibious capability by considering floatability, stability and resistance/propulsion characteristics. Initial resistance and flow visualization simulation showed that the flow velocity entering into the under keel clearance space increased due to low water depth and passed the certain amount of flow under multi-purpose amphibious vehicle. So the hydrodynamic resistance increased due to boundary layer expansion on bottom in turbulent flow regime (Helvacioglu, et al. 2011).

Traditionally, ships have been optimized for minimum fuel consumption in calm water. For amphibious vehicles, this has led to very blunt bow shapes. Such bow shapes have high added resistance due to waves and shallow water effects. Thus one might think that the optimum bow shape, when realistic wave conditions are taken into account, should be more slender or more hydrodynamic shapes than the current one. Furthermore, the operational area of the ship (the route it sails) could influence what is the optimum bow shape in shallow water. 
Amphibious vehicles such as amphibious assault vehicles and amphibious armored personnel carriers have been utilized in the military services for many years. Their mission specifications included the amphibious operations described as to be deployed from a ship in calm to moderate seas and to reach the shore at a reasonable time. They are usually powered by two water-jets at a maximum water-borne speed of about $13 \mathrm{~km} / \mathrm{h}$. On the other hand, most of these amphibious vehicles are designed for land operations only and their operations in water are limited to passing through rivers safely at a specified speed without satisfying floatation requirements. Therefore, the floatability and stability requirements of these vehicles are optional features required only for shallow water river operations (Nakisa, et al. 2015).

There are only a few published papers on the design principles of amphibious vehicles, which investigate the hydrodynamics characteristics in shallow water depth. Several water jet systems are investigated for Marine Corps applications (AAVs, 2005). A flush type waterjet propulsion unit is applied for a Multipurpose Amphibious Vehicles (MAV) that can cross rivers and lakes at a speed of $10 \mathrm{~km} / \mathrm{h}$ with a twin waterjet propulsion system. Self-propulsion tests were carried out by using a 1:5 scale amphibious model to estimatethe required effective power based on hydrodynamic results (Sticker, et al. 1994 and Chun, et al. 2003).

When we are considering the shallow water it is the restriction in vertical direction. Potential flow around the ship hull changes when ship encounters shallow water. Due to less under keel clearance (UKC) the flow beneath the ship plays a major role on resistance. Flow velocity increases beneath the ship bottom in shallow water compared to deep water. Flow velocity increase because there is a narrow passage for flow between ship bottom and sea bed. As the flow velocity increases there is a reduction in bottom pressure which is the source of upward buoyancy force. Thereafter the increase in MAV sinkage and trim may occur due to uneven reduction in pressure along the MAV length. Ship resistance increases, so there is an involuntary reduction in the speed. As a result for same resistance, ship speed in shallow water is lower than in deep water. If one wants to maintain the same speed in shallow water as in deep water the ship may face grounding due to excess sinkage and trim. So there is a voluntary speed reduction in restricted water depth region (Patel and Premchand, 2015).

\section{Modeling and Governing Equations}

The MAV is equipped with watertight compartments to achieve floatation capability. The vehicle is also equipped with additional water pumps in order to pump out the uncontrolled water ingress during the river crossing mission. The geometric design of MAV is shown in Figs.1-3. The Characteristics of Multipurpose Amphibious Vehicle are given in Table 1. Appendages, which are not a part of the main body such as wheels, drive trains etc. are considered as watertight compartments and added separately in stability calculations. In addition to floatability, the vehicle should also be stable in a floating condition. Free surface effect on the ship hull of multipurpose amphibious vehicle simulated using two body modeling in Ansys-CFX 14.0. The flow inlet has two parts as water inlet in shallow water area zone and air inlet above the free surface as shown in Fig.4. Fig. 4 and Table 2 show the computational domain and mesh elements which is modeled and simulated in Ansys-CFX 14.0 using Finite Volume Method (FVM) based on RANS equations. In Cartesian tensor form the general RANS equation for continuity can be written as below.

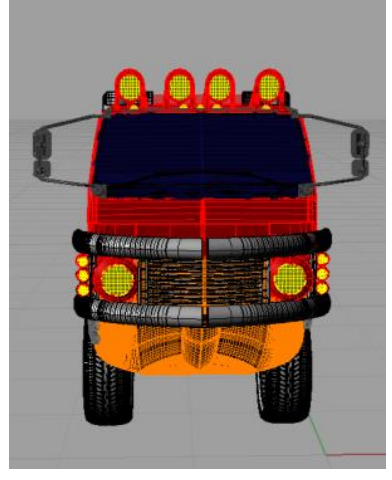

(a) Front view

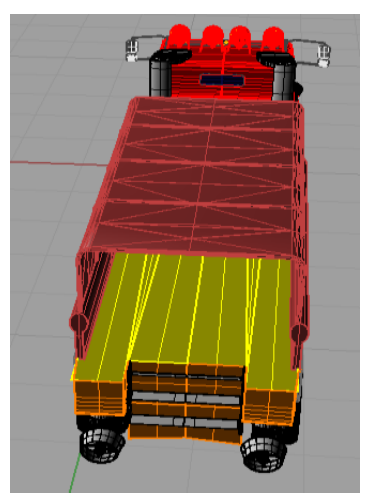

(b) Back view

Fig. 1: Multi-purpose amphibious vehicle 
Table 1: Particulars and coefficients of Multipurpose Amphibious Vehicle

\begin{tabular}{|c|c|c|c|}
\hline Loading Condition & Actual size & Model Size & Unit \\
\hline $\mathrm{L}_{\mathrm{WL}}$ & 6.607 & 1.65175 & $\mathrm{~m}$ \\
\hline Beam & 2.024 & 0.506 & $\mathrm{~m}$ \\
\hline Draft & 0.99 & 0.2475 & $\mathrm{~m}$ \\
\hline Displaced volume & 5.314 & 0.08303 & $\mathrm{~m}^{\wedge} 3$ \\
\hline Wetted area & 31.719 & 0.33212 & $\mathrm{~m}^{\wedge} 2$ \\
\hline Prismatic coeff. & 0.559 & 0.559 & ------ \\
\hline Waterplane area coeff. & 0.665 & 0.665 & ------ \\
\hline LCG from midships & 2.726 & 0.6815 & $\mathrm{~m}$ \\
\hline Transom draft & 0.025 & 0.00625 & $\mathrm{~m}$ \\
\hline Max sectional area & 1.438 & 0.08987 & $\mathrm{~m}^{\wedge} 2$ \\
\hline Deadrise at 50\% LWL & 19.33 & 19.33 & $\mathrm{deg}$. \\
\hline Hard chine or Round & Round bilge & Round bilge & ------ \\
\hline bilge & 0 & 0 & $\mathrm{kts}$ \\
\hline Headwind & 1 & 4 & ------ \\
\hline Scale & 0.001 & 0.001 & tonne/m^3 \\
\hline Air density & $1.1883 \mathrm{E}-06$ & $1.1883 \mathrm{E}-06$ & $\mathrm{~m}^{\wedge} 2 / \mathrm{s}$ \\
\hline Kinematic viscosity & 1.025 & 1.00 & tonne/m^3 \\
\hline Water Density & & & \\
\hline
\end{tabular}

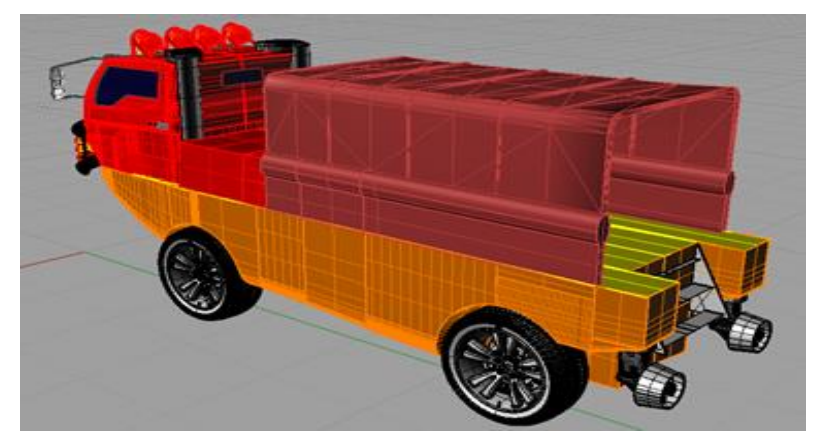

Fig. 2: Side view of Multipurpose Amphibious Vehicle

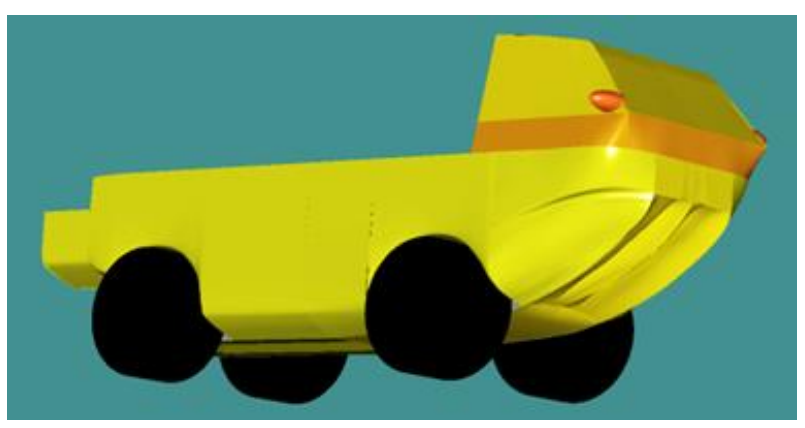

Fig. 3: Simplified MAV model for using in simulation 


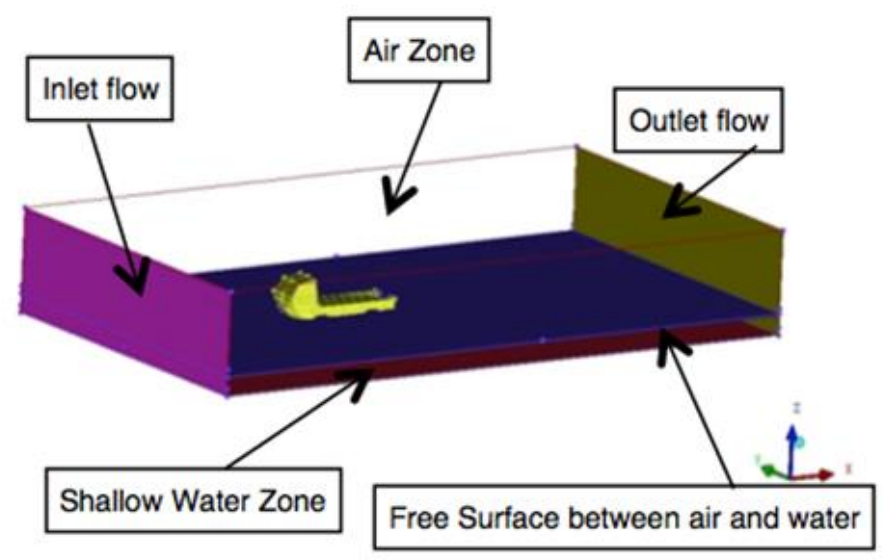

Fig. 4: Multipurpose Amphibious Vehicle in shallow water computational domain

Table 2: Mesh elements number

\begin{tabular}{|c|c|}
\hline Total Elements & Total Nodes \\
\hline 734,273 & 125,942 \\
\hline
\end{tabular}

The governing equation for mass is given by:

$\frac{\partial \rho}{\partial t}+\frac{\partial\left(\partial u_{i}\right)}{\partial x_{i}}=0$

and for momentum:

$\frac{\partial\left(\rho u_{i}\right)}{\partial t}+\frac{\partial\left(\rho u_{j} u_{i}\right)}{\partial x_{j}}=-\frac{\partial \rho}{\partial x_{i}}+\frac{\partial}{\partial x_{i}}\left[\mu\left(\frac{\partial u_{i}}{\partial x_{j}}+\frac{\partial u_{j}}{\partial x_{j}}-\frac{2}{3} \delta_{i j} \frac{\partial u_{i}}{\partial x_{i}}\right)\right]+\frac{\partial}{\partial x_{i}}\left(-\rho \overline{u_{i}^{\prime} u_{j}^{\prime}}\right)+f_{b i}$

In the above equations, $u_{i}$ is ith Cartesian component of total velocity vector, $\mu$ is molecular viscosity, $\left(-\rho \overline{u_{i}^{\prime} u_{j}^{\prime}}\right)$ is Reynolds stress, $\delta_{i j}$ is Kronecker delta and $\mathrm{p}$ is static pressure. The Reynolds stress should be demonstrated to near the governing equations by suitable turbulent model. For solution the RANS equation and turbulence velocity time scale, it is used by Boussinesq's eddy-viscosity supposition and two transport equations. The body force is expressed by $\mathrm{f}_{\mathrm{bi}}$ (Fox, et al. 2006).

The shear stress transport (SST) turbulence model had been used in this study, because it gives the best results in comparison with other turbulence models. The equations are shown as follows:

Equation of $\kappa$ :

$\frac{\partial}{\partial t}(\rho k)+\frac{\partial}{\partial x_{i}}\left(\rho k u_{i}\right)=\frac{\partial}{\partial x_{j}}\left(\Gamma_{k} \frac{\partial k}{\partial x_{j}}\right)+G_{k}-Y_{k}+S_{k}$

Equation of $\omega$ :

$\frac{\partial}{\partial t}(\rho \omega)+\frac{\partial}{\partial x_{i}}\left(\rho \omega u_{i}\right)=\frac{\partial}{\partial x_{j}}\left(\Gamma_{\omega} \frac{\partial \omega}{\partial x_{j}}\right)+G_{\omega}-Y_{\omega}+D_{\omega}+S_{\omega}$

Where $G_{\kappa}$ and $G_{\omega}$ express the generation of turbulence kinetic energy due to mean velocity gradients and $\omega$. $\Gamma_{\kappa}$ and $\Gamma_{\omega}$ express the active diffusivity of $\kappa$ and $\omega . Y_{\kappa}$ andY ${ }_{\omega}$ represent the dissipation of $\kappa$ and $\omega$ due to

Numerical estimation of shallow water effect on multipurpose amphibious vehicle resistance 
turbulence. $\mathrm{D}_{\omega}$ expresses the cross-diffusion term, $\mathrm{S}_{\mathrm{\kappa}}$ and $\mathrm{S}_{\omega}$ are user-defined source terms (Sticker, et al. 1994 and Chun, et al. 2003).

The computational setting for using the ANSYS-CFX is tabulated in Table 3 as follows:

Table 3: computational setting

\begin{tabular}{|l|l|}
\hline \multicolumn{1}{|c|}{ Parameter } & \multicolumn{1}{c|}{ Setting } \\
\hline Computing & 64-bit Desktop pc 16GB of RAM \\
\hline Simulation type & Steady state \\
\hline Mesh type & Unstructured hybrid(tetrahedral/prism) \\
\hline Turbulence model & k-w ( Shear stress transport) \\
\hline Wall modelling Automatic & wall function based on a law of the wall formulation \\
\hline Advection scheme & CFX high resolution \\
\hline
\end{tabular}

\section{Calm Water Resistance}

The calm water resistance needs to be established together with the added resistance for the different water depth to be able to evaluate the total resistance of the v-shape bow design on a typical voyage.The goal of the calm water resistance analysis is to establish a resistance curve for comparing of different water depth. The argumentation is that empirical methods are based on main characteristics of the ship and will not be able to properly account for details in the design of the amphibious vehicle in shallow water area. The calm water resistance is decomposed into different contributions. Two major components are the viscous resistance and the wave making resistance. The total resistance in calm water can be decomposed as:

$C T s=C R+(1+k) *(C F s+\Delta C F)+C A p p s+C A A s+C D B s$

CTs : Total resistance coefficient in MAV scale

CR : Residual resistance coefficient

CFs : Skin friction coefficient in MAV scale

$\Delta \mathrm{CF}:$ Hull roughness coefficient

CApps : Appendages resistance coefficient in MAV scale

CAAs : Air resistance coefficient for MAV

CDBs : Resistance coefficient of transom stern in MAV scale

The residual resistance is composed of several components. There is no standard decomposition of this coefficient, which may contribute to difficulties in comparison of results. One major component of the residual coefficient is the wave making resistance $(\mathrm{CW})$, which again can be composed to wave pattern resistance and wave breaking resistance (Larsson and Raven, 2010). 


\section{Results and Discussion}

Fig. 5 shows the flow velocity contours around the ship hull. The flow velocity at ship bow is lower than other zones. The flow velocity around the bow shoulders is higher than stern shoulders as shown in Fig. 5. Fig. 6 shows the free surface wave height contour around the ship hull. The wave height at bow ship is higher than other area; also wave making resistance has an important role in total ship resistance due to the ship hull form of multipurpose amphibious vehicle. Fig. 7 shows the pressure distribution contours around the ship hull. The pressure on the bow of the ship hull is higher than other area as shown in Fig. 7. Total calm water resistance against ship speeds are shown in Fig. 8. Considering to following resistance graphs, the Multi-purpose amphibious vehicle in shallowest water depth has higher resistance in compare of other water depth because in lowest water depth the under keel clearance is small and the flow velocity has more increased. So, the increase in resistance in shallow water as compared to deep water at same speed is significantly noticeable. In shallow water the velocity of flow under the keel increases so there is a significant drop in pressure. As a result buoyancy, which is the upward force to the ship, decreases. So the MAV sunk further from its original draft. As a result there is increased in resistance. When the flow velocity increased the hydrodynamic resistance is increased. In addition, this phenomena cause to increase the frictional resistance, added resistance and pressure resistance due to ship squat.

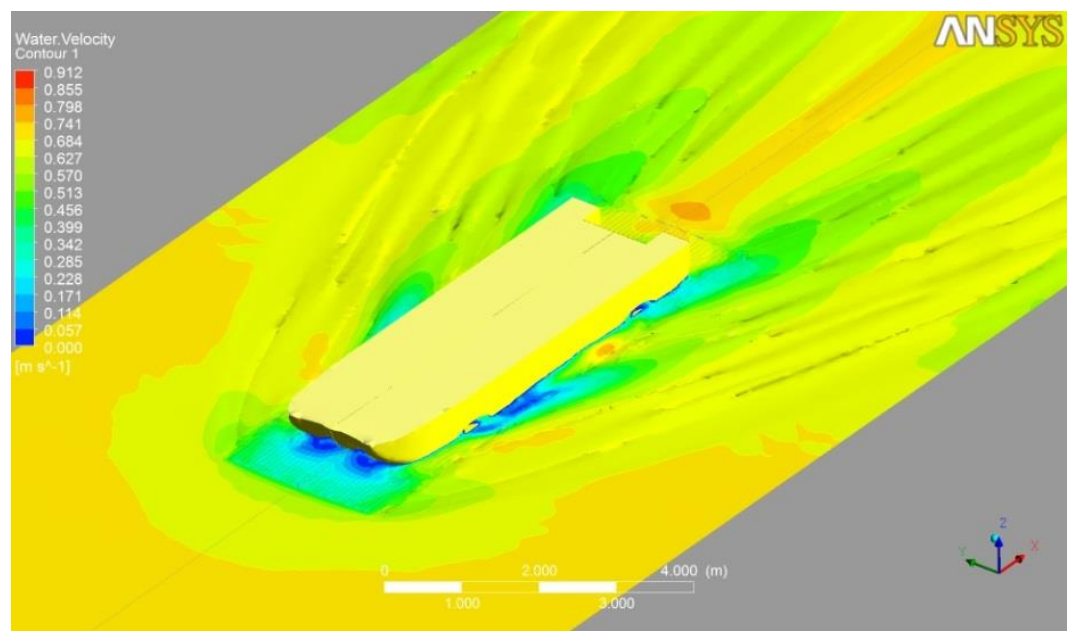

Fig. 5: Flow velocity contour around ship hull

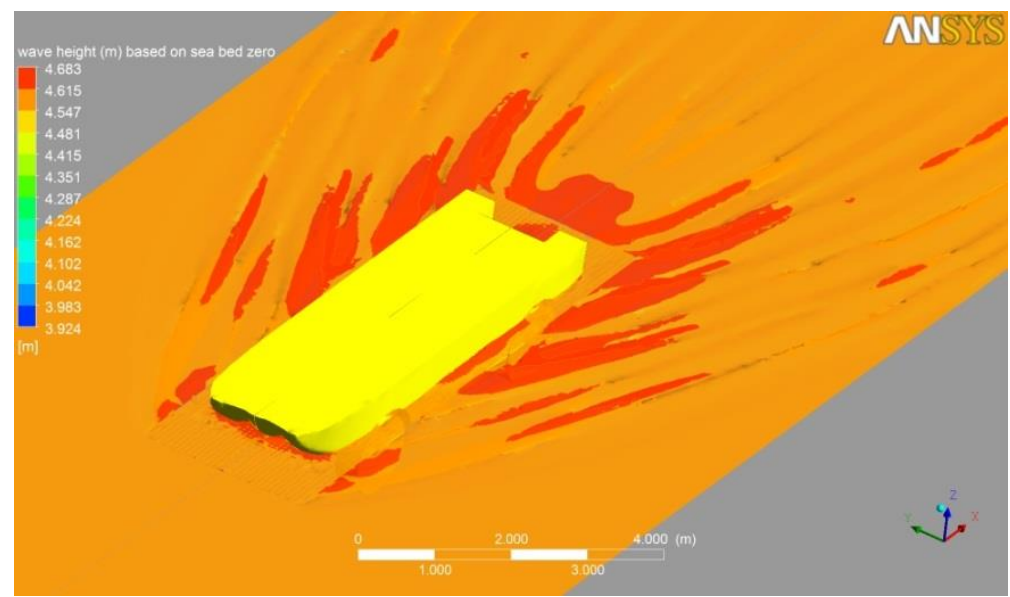

Fig. 6: Wave height contour around ship hull 


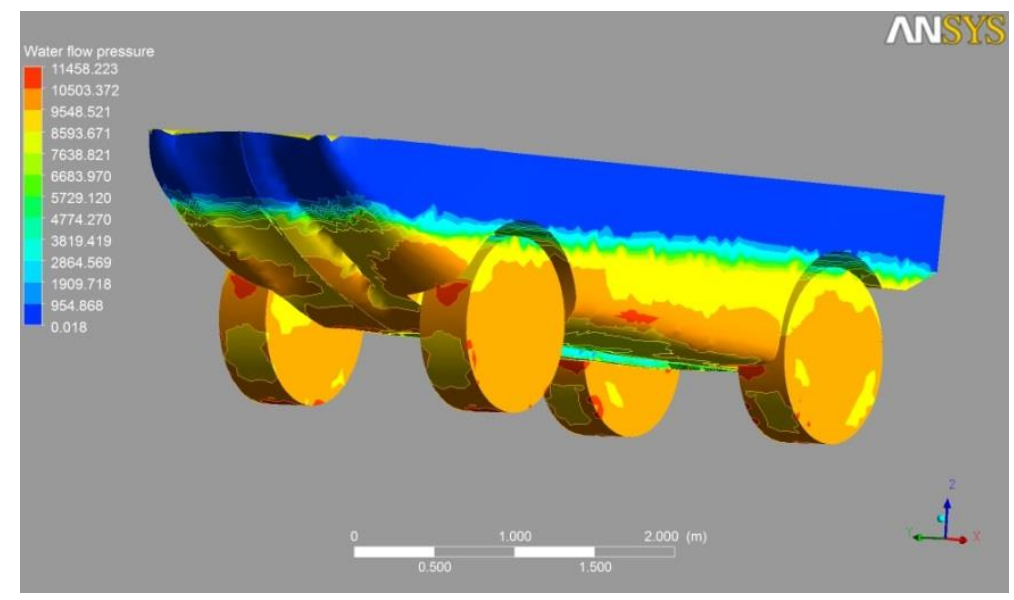

Fig. 7: Pressure contour around ship hull

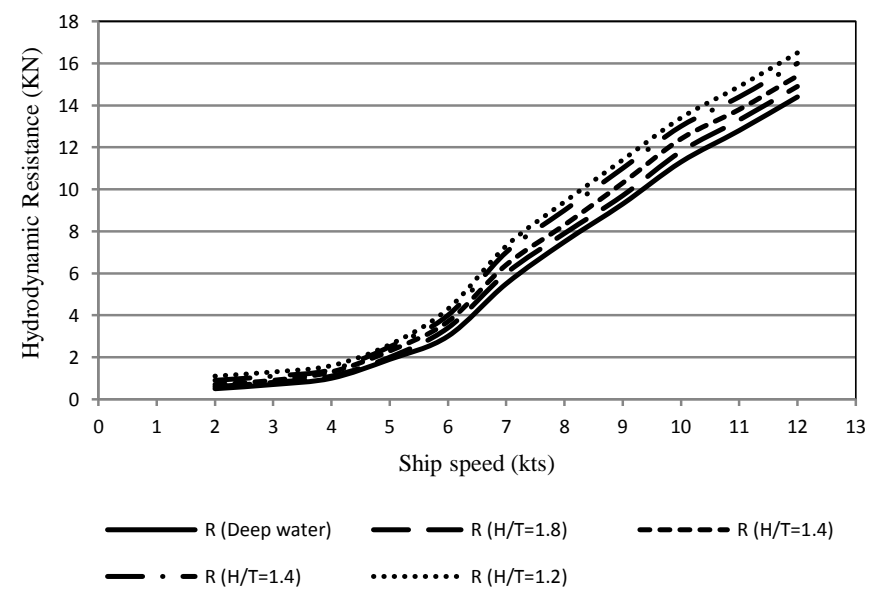

Fig. 8: Hydrodynamic resistance of MAV in different water depth versus ship speed.

\section{Conclusion}

This research has investigated the shallow water effects on hydrodynamic resistance for multipurpose amphibious vehicle in different speeds using computational fluid dynamics method.The increase in resistance in shallow water as compared to deep water at same speed is significantly noticeable. The flow velocity under the ship hull in shallow water is higher than that in deep water. As the research shows, the hydrodynamic pressure distribution on the ship hull has an important role on ship resistance. Due to increase in flow under the keel there is a reduction in pressure in that region, as a result buoyancy decreases and results in sinkage and trim. As the sinkage of ship occurs, wetted surface area increases, as a result viscous drag increases.

\section{Acknowledgement}

This research was supported by Universiti Teknologi Malaysia (UTM) - Marine Technology Centre (MTC), MOHE using vote project No.: Q.J130000.2409.03G00.

\section{References}

Alexander, R. and Alexander, R. M. (1963): Design of landing craft for marine corps action, Naval Engineering Journal, 75(1): pp. 163-170). https://doi.org/10.1111/j.1559-3584.1963.tb04673.x 
Carl, D. (1965): New amphibious vehicle progress part 3 landing craft, assault LCA and landing vehicle hydrofoil (LVH), Naval Engineering Journal, 77(3):18-25.

Chun, H. H., Ahn, B. H. and Cha, S. M. (2003): Self-propulsion test and analysis of an amphibious tracked vehicle with water jet, Proceeding of World Maritime Technology Conference and SNAME Annual Meeting, USA, 6 (133).

Foss, C. (2003): Jane's tank and combat vehicle recognition guide, Harper Collins, New York.

Fox, G. A, Wilson, G. V. Periketi, R. K., Cullum, B. F (2006): A sediment transport model for seepage erosion of streambanks, Journal of Hydrologic Engineering, 11 (6), 603-611. https://doi.org/10.1061/(ASCE)1084$\underline{0699(2006) 11: 6(603)}$

Haddock, G. and Latorre, R. (1995): A look back on 1942 combat and production, an example of successful employee empowerment at Higgins Industries, Journal of Ship Production, 11(3): 159-170.

Helvacioglu, S., Helvacioglu I. H. and Tuncer, B. (2011): Improving the river crossing capability of an amphibious vehicle, Ocean Engineering, 38: 2201-2207. https://doi.org/10.1016/j.oceaneng.2011.10.001

Marine Corps War fighting Publication, Employment of Amphibious Assault Vehicles (AAVs) (2005): http://www.doctrine.usmc.mils, MCWP 3-13.

Nakisa, M., Maimun, A., Yasser M. Ahmed, Behrouzi, F., Steen, S. and Tarmizi, A. (2015): Hydrodynamic resistance analysis of new hull design for multipurpose amphibious vehicle applying with finite volume method, JurnalTeknologi (Sciences and Engineering), 74(5): 73-76. https://doi.org/10.11113/jt.v74.4644

Nakisa, M., Malik, A. M. A, Ahmed, Y. M. , Steen, S. , Behrouzi, F. , Hassanzadeh, R. and Sabki, A. F. (2014): Propeller effect on 3D flow at the stern hull of a LNG carrier using finite volume method, Applied Mechanics and Materials, 554: 566-570. https://doi.org/10.4028/www.scientific.net/AMM.554.566

Nakisa, M., Maimun, A., Sian, A. Y., Ahmed, Y. M., Priyanto, A., Jaswar and Behrouzi, F. (2013): Threedimensional numerical analysis of restricted water effects on the flow pattern around hull and propeller plane of LNG ship, International Journal of Mechanics, 3 (7): 234-241.

Patel, P. K. and Premchand, M. (2015): Numerical investigation of the influence of water depth on ship resistance, International Journal of Computer Applications, 116(17):10-17. https://doi.org/10.5120/19279-0692

Sticker, J.G., Becnel A. J. and Purnell, J. G. (1994): Advanced water jet systems, Naval Engineering Journal, 106 (5): 100-109. https://doi.org/10.1111/j.1559-3584.1994.tb02338.x 